\title{
Alcohol Intake by Workers in a Health Care Institution in Bucaramanga, Colombia
}

\author{
Edna M. Gamboa-Delgado ${ }^{1}$, Doris C. Quintero-Lesmes ${ }^{2}$ \& Oscar F. Herrán ${ }^{1}$ \\ ${ }^{1}$ Escuela de Nutrición y Dietética, Universidad Industrial de Santander, Bucaramanga, Colombia \\ ${ }^{2}$ Fundación Cardiovascular de Colombia, Floridablanca, Colombia \\ Correspondence: Edna M. Gamboa-Delgado, Carrera 32 N²9-31. Escuela de Nutrición y Dietética, Facultad de \\ Salud. Universidad Industrial de Santander. Bucaramanga, Colombia. E-mail: magalygamboa@yahoo.com; \\ emgamboa@uis.edu.co
}

Received: August 13, 2018 Accepted: September 17, 2018 Online Published: October 13, 2018

doi:10.5539/gjhs.v10n11p95 URL: https://doi.org/10.5539/gjhs.v10n11p95

\begin{abstract}
The harmful alcohol intake represents a global problem. Its high consumption has been associated with cardio metabolic risk factors. Evaluating their consumption in health workers is important for the formulation of strategies to promote healthy lifestyles. The objective of this study was to determine the consumption of alcohol and establish the differences of this intake in terms of socio-demographic and cardiovascular characteristics of interest in hospital workers of Bucaramanga, Colombia.

An analytical cross sectional was made (baseline of an intervention study to reduce cardiovascular risk factors). Sociodemographic, anthropometric, biochemical, physical activity, and lifestyles characteristics, as well as alcohol consumption (g / week) were evaluated using a previously validated Frequency Alcohol Questionnaire. Multiple linear regression models were used, adjusting for sex, age, socio-economic level, schooling and marital status.

$77.4 \%$ (95\% CI: $71.2 \%$ to $82.8 \%$ ) of the study participants consumed some type of alcoholic beverage during the month prior to the survey, with an average of 70.0 grams of alcohol per week of $70.0 \mathrm{~g}$. We found a statistically significant difference $(\mathrm{p}=0.012)$ of 40.4 grams of alcohol per week $(95 \% \mathrm{CI}: 8.9$ to $71.8 \mathrm{~g} /$ week) consumed among those who have hypertriglyceridemia and those who do not.

In conclusion, the high consumption of grams of alcohol per week is related to a triglyceride level above the normal ranges.
\end{abstract}

Keywords: alcohol drinking, workers, occupational health, triglycerides, cardiovascular abnormalities

\section{Introduction}

The World Health Organization (WHO) has declared the harmful consumption of alcoholic beverages to be a global problem that endangers both the individual and the social development of the population (Panamerican Health Organization, 2014). Alcohol is a psychoactive substance, which in excess affects the central nervous system and some organs, as well as social and labor relationships with peers (Ardila \& Herran, 2008). In 2010, per capita alcohol consumption was 6.2 liters for the worldwide population over 15 years of age. This translates into approximately 13.5 grams of alcohol per day (Panamerican Health Organization, 2014). It has been found that approximately $16.0 \%$ of drinkers over the age of 15 occasionally consume alcohol (Panamerican Health Organization, 2014). In Latin America and the Caribbean, an average of 8.4 liters of pure alcohol is consumed per year, which is 2.2 liters more than the worldwide average, according to the first report on alcohol published for the region (WHO, 2015). This report ranks Colombia as 12th out of 37 countries in the region, with 6.2 liters per capita annual consumption (WHO, 2015).

In Bucaramanga, Colombia, previous studies have shown that adult men and women consume alcohol at toxic levels every seven days, on average. And over the past decade, the risk of alcoholism in this population has surpassed that of the national population ( $42 \%$ vs. $35 \%$, respectively) (Ministerio de Salud y Protección Social, 2013). In addition, variables such as sex, age, socio-economic level, and enjoying drinking have been associated with alcohol consumption (Herran \& Ardila, 2009a; Herran \& Ardila, 2009b).

In the global context, alcohol consumption has been both positively and negatively associated with certain public 
health events (Haver, Gjestad, Lindberg, \& Franck, 2009; Murray et al., 2002; Rehm, Greenfield, \& Rogers, 2001; Corrao, Rubbiati, Bagnardi, Zambon, \& Poikolainen, 2000). Daily alcohol consumption limits of up to 20 grams for women and 40 grams for men have been shown to present a lower risk to health. And a protective effect has been found on the development of cardiovascular events, with as much as a $25 \%$ reduction in coronary events (Rimm, Williams, Fosher, Criqui, \& Stamper, 1999).

However, the consumption of alcohol alone, and at toxic levels, is associated with violence and traffic accidents (Herran \& Ardila, 2005), and consuming a larger amount of alcohol is negatively related to more than 200 diseases and injuries, including risk of developing cancer of the liver and of the gastrointestinal tract (Panamerican Health Organization, 2014; Morgan, Mandayam, \& Jamal, 2004; Gronbaek et al., 1998), impaired lipid metabolism, and increased levels of triglycerides in the blood (Miguel Soca, 2009).

Evidence suggests that a direct relationship exists between alcohol consumption and a high triglyceride concentration. This is explained by the metabolism of alcohol, which occurs mostly in the liver through liver enzymes that are altered when the consumption of alcohol is chronic or excessive. This process interferes with the metabolism of the VLDL apolipoprotein, a lipoprotein which is responsible for transporting triglycerides. Thus, when the liver functions improperly, these triglycerides accumulate in the liver and the blood, since the lipoprotein that transports them is lacking. This has been found to occur when the daily consumption of alcohol exceeds 30 grams, which is equivalent to one glass of alcohol such as cognac and whiskey. In the case of beer or similar beverages, the concentration of triglycerides in blood is not due to the alcohol itself, but rather to the sugar contained in these types of alcoholic beverages. When consumption is excessive, a portion of these sugars is derived from the synthesis of triglycerides, which are deposited in adipose tissue (Miguel Soca, 2009).

Only a few studies have indicated that alcohol consumption significantly affects job performance, which mainly translates into poorer work performance (Ochoa, 2011), higher rates of absenteeism, a higher risk of occupational accidents, and a notable increase in premature deaths, due to both acute and chronic diseases (Chagas, Gaunekar, Patel, Kukalekar, \& Fernandes, 2003; Lapham, Gregory, \& McMillan, 2003; Lapham, Gregory, \& McMillan, 2003).

This study was proposed because of a lack of knowledge about alcohol consumption and its relationship with cardiometabolic risk factors in a population of health sector workers who know the implications of excessive alcohol consumption and who make recommendations regarding moderate consumption. Its aim was to determine alcohol consumption in a population of workers in a health care institution in Bucaramanga, Colombia, and identify the differences in consumption in terms of the sociodemographic and cardiovascular characteristics of interest.

\section{Methods}

An analytical, cross-sectional study was carried out of workers at a high-complexity health care institution in Colombia, using the baseline from an intervention study to reduce cardiovascular risk factors.

All workers were invited to participate in the study, and those who agreed to participate in the first phase and who had a current contract with the health care institution were included. Pregnant women were excluded from the study.

Data was collected at two appointments. After obtaining written informed consent, participants filled out a self-administered survey at the first appointment, which included data regarding sociodemographics, physical activity, alcohol consumption, smoking, and personal and family history of cardiovascular risk. A second appointment was scheduled, for which participants were asked to wear light clothes, fast for 8 to 10 hours, and to not have performed intense physical activity or ingested alcohol.

During this appointment, a physical examination was conducted, anthropometric measurements and blood pressure were taken, and blood samples were collected.

\subsection{Variables}

The dependent variable for this study was the consumption of alcohol in grams per week. In addition, the prevalence of alcohol consumption during the month prior to the survey was estimated using the alcohol consumption frequency questionnaire, which was validated for the Colombian population (Herran \& Ardila, 2006). This questionnaire was used to evaluate the approximate frequency of alcohol consumption by the subjects over the previous month, by group of alcoholic beverage (beer, brandy, rum, wine, whiskey, others).

This study also analyzed variables such as age, sex, socioeconomic status, monthly income, education level, marital status, social security, profession, family history of first-degree relatives, history of cerebrovascular or 
cardiovascular disease before age 60, and history of cancer. Body composition, tobacco consumption, and physical activity were also investigated, and metabolic cardiovascular risk factors were analyzed, including: large waist circumference ( $\geq 90 \mathrm{~cm}$ for men and $\geq 80 \mathrm{~cm}$ for women) (IDF, 2006), hip-waist index ( $>0.90$ for men and $>0.85$ for women) (Lear, James, \& Kumanyka, 2010), body mass index ( $\geq 25 \mathrm{~kg} / \mathrm{m}^{2}$ for overweight and $\geq 30 \mathrm{~kg} / \mathrm{m} 2$ for obesity) (WHO, 2000), blood pressure (systolic blood pressure (SBP) $>140 \mathrm{~mm} \mathrm{Hg}$ or diastolic blood pressure (DBP) $>90 \mathrm{~mm} \mathrm{Hg}$ ) (The National High Blood Pressure Education Program Coordinating Committee, 2003), fasting glucose (diabetes when fasting glucose $\geq 126 \mathrm{mg} / \mathrm{dl}$ ) (ADA, 2014), total cholesterol (> $200 \mathrm{mg} / \mathrm{dl}$ ) (26), triacylglycerols ( $>150 \mathrm{mg} / \mathrm{dl}$ ) (26), HDL cholesterol ( $<40 \mathrm{mg} / \mathrm{dl}$ for men and $<50 \mathrm{mg} / \mathrm{dl}$ for women) (26), and LDL cholesterol (> $130 \mathrm{mg} / \mathrm{dl}$ ) (National Cholesterol Education Program, 2002).

Physical activity was assessed using the short version of the International Physical Activity Questionnaire-IPAQ, which was adapted to the Colombian population. The questionnaire took into account the urban and social context of low- and middle-socioeconomic levels, since these strata represent the largest proportion of the national population (Mantilla \& Gómez-Conesa, 2007).

A description of the data collection process for all of the variables has been described in detail previously (Gamboa, et al., 2015). All the data were collected by a team composed of four professional nurses and a nutritionist duly trained in standardized techniques for collecting information.

\subsection{Statistical Analysis}

The data analysis was aimed at determining alcohol consumption (in grams per week) and associated factors. A descriptive analysis of the main characteristics of the study population was carried out. In the case of asymmetric distributions, we decided to use the median and the interquartile range (25-75\%), given that these are not as affected by extreme values.

The categorical variables were described as proportions, with their respective $95 \%$ confidence intervals $(95 \% \mathrm{CI})$.

The Mann-Whitney test was applied given that some of the continuous variables were not normally distributed. Fisher's exact test was used for the categorical variables.

Multiple linear regression models (Greenland, 1989) were adjusted for alcohol consumption (g/ week) using the sociodemographic and cardiovascular characteristics of interest as the main independent variables, and adjusting by sex, age, socio-economic level, schooling, and marital status. All of the model assumptions (residual normality, linearity, and homoscedasticity) were verified and goodness-of-fit tests were performed.

The survey data were entered into a database, in duplicate, and validated using the EpiInfo program, version 6.04d (CDC, EpiInfo, 2001) (CDC, 2001). The analyses were performed using the Stata statistical program, version 12.1 / IC (Statistics Data Analysis, STATA \ICq 12.1).

\subsection{Ethical Considerations}

This study is classified as minimum risk in accordance with 1993 resolution number 08430 by the Ministry of Health of Colombia, which establishes the scientific, technical, and administrative standards for health research (Ministerio de Salud, 1993). The protocol for this research was approved by the Scientific Technical Committee and the Research Ethics Committee of a health care institution in Colombia. All participants signed informed consent.

\section{Results}

A total of 227 workers were analyzed (the response rate was $87 \%$ ), $63.4 \%$ of which were female. The median age of all of the subjects was 29 years of age, with an interquartile range (IR) of 12 years. A total of $65.2 \%$ of the respondents belonged to the middle socioeconomic stratum, while $29.0 \%$ belonged to the low and $5.7 \%$ to the high stratum. A total of $34.3 \%$ of study subjects presented overweight and $9.0 \%$ were obese.

Statistically significant differences were found for monthly income, physical activity level during the week prior to the survey, and history of hypertension and dyslipidemia $(p=0.009, p=0.000, p=0.004$, and $p=0.003$, respectively) (Table 1). A greater proportion of women than men earned less than $\$ 1,600,000$ Colombian pesos (average value equivalent to $\$ 761.9$ USD at the time of the survey [1 USD $=\$ 2,100$ Colombian Pesos]). The women had a low or moderate level of physical activity during the week prior to the survey, and their personal history of hypertension was greater than the men, while a greater proportion of men had a personal history of dyslipidemias. 
Table 1. Overall characteristics of workers in a health care institution in Colombia

\begin{tabular}{|c|c|c|c|c|}
\hline Characteristics & $\begin{array}{l}\text { All }(\mathbf{n}=\mathbf{2 2 7}) \\
\mathrm{n}(\%) \text { ó } \\
\text { Median [IR] }\end{array}$ & $\begin{array}{l}\text { Women }(n=144) \\
\text { n (\%) ó } \\
\text { Median [IR] }\end{array}$ & $\begin{array}{l}\text { Men (n=83) } \\
\text { n (\%) ó Median [IR] }\end{array}$ & p Value \\
\hline \multicolumn{5}{|l|}{ Sociodemographic Characteristics } \\
\hline Age (years) & $29[12.0]$ & 30 [11.0] & $28[9.0]$ & $0.105 £$ \\
\hline \multicolumn{5}{|l|}{ Socioeconomic level } \\
\hline Low & $66(29.0)$ & $44(66.6)$ & $22(33.3)$ & $0.378 \ddagger$ \\
\hline Medium & $148(65.2)$ & $94(63.5)$ & $54(36.4)$ & \\
\hline High & $13(5.7)$ & $6(46.1)$ & $7(53.8)$ & \\
\hline \multicolumn{5}{|l|}{ Monthly income } \\
\hline Under $\$ 1,600,000 ¥$ & $153(67.4)$ & $106(69.2)$ & $47(30.7)$ & $0.012 *$ \\
\hline$\$ 1,600.000$ or more & $74(32.6)$ & $38(51.3)$ & $36(48.6)$ & \\
\hline \multicolumn{5}{|l|}{ Highest level of schooling } \\
\hline Secondary or technical & $85(37.4)$ & $52(61.1)$ & $33(38.5)$ & $0.669 \$$ \\
\hline University or postgraduate & $142(62.5)$ & $92(64.7)$ & $50(35.2)$ & \\
\hline \multicolumn{5}{|l|}{ Marital Status } \\
\hline Single & $141(62.1)$ & $89(63.1)$ & $52(36.8)$ & $0.988 \ddagger$ \\
\hline Married or Free Union & $78(34.3)$ & $50(64.1)$ & $28(35.9)$ & \\
\hline Divorced, Separated or Widowed & $8(3.5)$ & $5(62.5)$ & $3(37.5)$ & \\
\hline \multicolumn{5}{|l|}{ Lifestyle } \\
\hline \multicolumn{5}{|l|}{ Current Smoker } \\
\hline No & $63(80.7)$ & $30(47.6)$ & $33(52.3)$ & $0.774 \ddagger$ \\
\hline Yes & $15(19.2)$ & $6(40.0)$ & $9(60.0)$ & \\
\hline \multicolumn{5}{|l|}{ Physical Activity Level § } \\
\hline Low & $119(52.4)$ & $89(74.7)$ & $30(25.2)$ & $0.000 \div$ \\
\hline Moderate & $73(32.1)$ & $45(61.6)$ & $28(38.3)$ & \\
\hline High & $35(15.4)$ & $10(28.5)$ & $25(71.4)$ & \\
\hline \multicolumn{5}{|l|}{ Nutritional Status } \\
\hline Underweight (BMI $<18.5 \mathrm{~kg} / \mathrm{m}^{2}$ ) & $4(1.8)$ & $3(75.0)$ & $1(25.0)$ & $0.093 *$ \\
\hline Normal Weight (BMI 18.6 to $24.99 \mathrm{~kg} / \mathrm{m}^{2}$ ) & $121(54.7)$ & $83(68.6)$ & $38(31.4)$ & \\
\hline Overweight (BMI 25.00 to $29.99 \mathrm{~kg} / \mathrm{m}^{2}$ ) & $76(34.3)$ & $39(51.3)$ & $37(48.6)$ & \\
\hline Obese (BMI $\geq 30 \mathrm{~kg} / \mathrm{m}^{2}$ ) & $20(9.0)$ & $13(65.0)$ & $7(35.0)$ & \\
\hline \multicolumn{5}{|l|}{ Alcohol Consumption (grams/week) } \\
\hline None & $48(22.5)$ & $29(20.2)$ & $19(39.5)$ & $0.287 \ddagger$ \\
\hline First Tertile (11.8 to 31.7 ) & $64(38.7)$ & $47(73.4)$ & $17(26.5)$ & $0.506 \ddagger$ \\
\hline Second Tertile (31.7 to 66.5 ) & $46(27.8)$ & $32(69.5)$ & $14(30.4)$ & \\
\hline Third Tertile (66.7 to 370.8 ) & $55(33.3)$ & $35(63.6)$ & $20(36.3)$ & \\
\hline \multicolumn{5}{|l|}{ Morbidity (personal history of CD) } \\
\hline High blood pressure (\%Yes) & $8(3.5)$ & $5(62.5)$ & $3(37.5)$ & $0.004 \div$ \\
\hline Dyslipidemias (\%Yes) & $13(5.7)$ & $6(46.1)$ & $7(53.8)$ & 0.003 \\
\hline Diabetes Mellitus (\%Yes) & $1(0.4)$ & $1(100.0)$ & $0(0.0)$ & $0.195 \ddagger$ \\
\hline Cancer (\% Yes) & $1(0.4)$ & $0(0.0)$ & $1(100.0)$ & $0.229+$ \\
\hline
\end{tabular}

IR: Interquartile Range; BMI: Body Mass Index; CD: Chronic diseases. $\$$ : $p$ value determined with Fisher’s exact test. $£: p$ value determined with the Mann-Whitney test. $¥: \$ 1,600,000$ Colombian pesos is an average value equivalent to \$761.9 USD as of the date of the survey ( $\$ 1 \mathrm{USD}=\$ 2,100$ Colombian pesos). $\S$ : Low physical activity: people who did not perform any type of physical activity or some physical activity but not enough to meet the criteria for moderate or high levels. 
Moderate physical activity: those who met any one of the following three criteria: 1) three or more days of vigorous physical activity for at least 20 minutes/day, 2) five or more days of moderate or vigorous physical activity and/or walking at least 30 minutes/day, or 3) five or more days of any combination of moderate physical activity, vigorous activity, and walking, with an energy expenditure of at least 600 MET minutes/week. High physical activity: those who met either one of the following two criteria: 1) vigorous physical activity at least three days/week with a minimum energy expenditure of 1,500 MET minutes/week or 2) seven or more days of any combination of walking, moderate physical activity, or vigorous activity with an energy expenditure of at least 3,000 MET minutes/week (Karolinska Institute, 2005).

\subsection{Alcohol Consumption}

A total of $77.4 \%$ (95\% CI: $71.2 \%$ to $82.8 \%$ ) of the study participants consumed some type of alcoholic beverage during the month prior to the survey, with an average of $70.0 \pm 69.4$ grams per week of alcohol. Of the total people who consumed an alcoholic beverage, $69.0 \%$ were women and $30.9 \%$ men. Nevertheless, there were no statistically significant differences in alcohol consumption according to sex $(p=0.492)$ or age $(p=0.560)$, schooling $(\mathrm{p}=0.654)$, marital status $(\mathrm{p}=0.926)$, or with respect to the other sociodemographic variables (Table 2$)$.

Regarding the differences in alcohol consumption according to cardiovascular risk factors, a statistically significant difference $(\mathrm{p}=0.012)$ of 40.4 grams of alcohol per week $(95 \%$ CI: 8.9, $71.8 \mathrm{~g}$ / week) was found between those who had hypertriglyceridemia and those who did not (the equivalent of approximately four 1-ounce glasses of an alcoholic beverage, on average) (Table 2).

Table 2. Alcohol consumed (in grams) per week by Colombian health workers, according to sociodemographic and cardiovascular characteristics

\begin{tabular}{|c|c|c|c|c|c|c|c|c|}
\hline Variable & $\mathbf{n}$ & Mean (g) & SD $(g)$ & $\mathbf{p} \dagger$ & $\begin{array}{l}\text { Adjusted } \\
\text { (g)¥ }\end{array}$ & Difference & CI 95\% & p \\
\hline \multicolumn{9}{|l|}{ Sex } \\
\hline Women & 143 & 52.3 & 63.6 & 0.544 & Ref & & $-12.9 ; 26.8$ & 0.492 \\
\hline Men & 70 & 58.3 & 75.8 & & 6.9 & & & \\
\hline \multicolumn{9}{|l|}{ Age group } \\
\hline Under 30 years & 111 & 51.2 & 64.7 & 0.492 & Ref & & $-14.1 ; 26.0$ & 0.560 \\
\hline 30 years and over & 102 & 57.6 & 71.0 & & 5.9 & & & \\
\hline \multicolumn{9}{|l|}{ Socio-economic level } \\
\hline Low & 63 & 44.4 & 48.3 & 0.452 & 16.4 & & $-4.9 ; 37.8$ & 0.484 \\
\hline Medium & 139 & 60.3 & 75.7 & & Ref & & & \\
\hline High & 11 & 34.2 & 38.1 & & & & & \\
\hline \multicolumn{9}{|l|}{ Monthly income } \\
\hline Under $\$ 1,600,000$ & 67 & 60.6 & 79.7 & 0.353 & Ref & & $-33.0 ; 14.5$ & 0.446 \\
\hline$\$ 1,600,000$ and over & 146 & 51.3 & 61.5 & & -9.2 & & & \\
\hline \multicolumn{9}{|l|}{ Education } \\
\hline Professional to postgraduate & 134 & 53.8 & 68.4 & 0.912 & Ref & & $-15.5 ; 24.7$ & 0.654 \\
\hline Secondary to Technical/technological & 79 & 54.9 & 66.9 & & 4.5 & & & \\
\hline \multicolumn{9}{|l|}{ Marital status } \\
\hline Single & 133 & 53.2 & 61.3 & 0.794 & Ref. & & $-19.6 ; 21.8$ & 0.926 \\
\hline Married or Free Union & 73 & 55.9 & 80.3 & & 1.0 & & & \\
\hline Separated, Divorced, or Widowed & 7 & 55.7 & 41.8 & & & & & \\
\hline
\end{tabular}


Cardiovascular Risk Factors

\begin{tabular}{|c|c|c|c|c|c|c|c|}
\hline \multicolumn{8}{|c|}{ Overweight or Obesity $^{1}$} \\
\hline No & 121 & 57.5 & 69.8 & 0.545 & Ref. & $-30.1 ; 10.5$ & 0.343 \\
\hline Yes & 86 & 51.7 & 66.7 & & -9.8 & & \\
\hline \multicolumn{8}{|c|}{ Hypercholesterolemia ${ }^{2}$} \\
\hline No & 172 & 54.7 & 69.1 & 0.835 & Ref. & $-27.2 ; 21.5$ & 0.819 \\
\hline Yes & 41 & 52.3 & 62.5 & & -2.8 & & \\
\hline \multicolumn{8}{|c|}{ Low HDL Cholesterol ${ }^{3}$} \\
\hline No & 193 & 55.1 & 69.8 & 0.676 & Ref & $-39.3 ; 31.6$ & 0.831 \\
\hline Yes & 17 & 47.9 & 44.7 & & -3.8 & & \\
\hline \multicolumn{8}{|c|}{ Hypertriglyceridemia $^{4}$} \\
\hline No & 191 & 50.02 & 59.9 & 0.006 & Ref & $8.9 ; 71.8$ & 0.012 \\
\hline Yes & 22 & 91.36 & 110.5 & & 40.4 & & \\
\hline \multicolumn{8}{|c|}{ High Blood Pressure } \\
\hline No & 199 & 54.6 & 68.8 & 0.787 & Ref & $-44.1 ; 31.4$ & 0.740 \\
\hline Yes & 14 & 49.5 & 51.8 & & -6.3 & & \\
\hline \multicolumn{8}{|c|}{ Impaired Fasting Glucose $^{6}$} \\
\hline No & 207 & 53.3 & 68.0 & 0.228 & Ref & $-33.8 ; 83.4$ & 0.405 \\
\hline Yes & 6 & 87.2 & 47.8 & & 24.8 & & \\
\hline
\end{tabular}

SD: standard deviation; CI 95\%: 95\% confidence interval; $\uparrow: p$ value estimated with simple linear regression models; $¥$ : adjusted differences using multiple linear regression models with differences in alcohol consumption in $\mathrm{g} /$ week (one of the variables of interest) as the result variable, and adjusted by sex, age, socio-economic level, education, and marital status; $\$ p$ value estimated with multiple linear regression.

1. Overweight or obesity: Body Mass Index (BMI) $\geq 25 \mathrm{~kg} / \mathrm{m}^{2} ; 2$. Hypercholesterolemia: greater or equal to $200 \mathrm{mg} / \mathrm{dl}$ total cholesterol; 3. low HDL cholesterol: under $30 \mathrm{mg} / \mathrm{dl}$ for men and under $50 \mathrm{mg} / \mathrm{dl}$ of C-HDL for women; 4. Hypertriglyceridemia: equal to or over $150 \mathrm{mg} / \mathrm{dl}$ of triglycerides; 5 . High blood pressure: systolic blood pressure equal to or over $140 \mathrm{~mm} \mathrm{HG}$ and/or diastolic pressure equal to or over $90 \mathrm{~mm} \mathrm{Hg}$; 6. Impaired fasting glucose: fasting glucose between 100 and $125 \mathrm{mg} / \mathrm{dl}$.

Regarding differences in the type of alcoholic beverages consumed during the month prior to the survey, the prevalence of beer, brandy, rum, and whiskey was higher for men than for women $(p<0.05)$ (Figure 1). Nevertheless, no significant differences in median alcohol consumption (expressed in grams per week) were found according to $\operatorname{sex}(\mathrm{p}=0.898)$. 


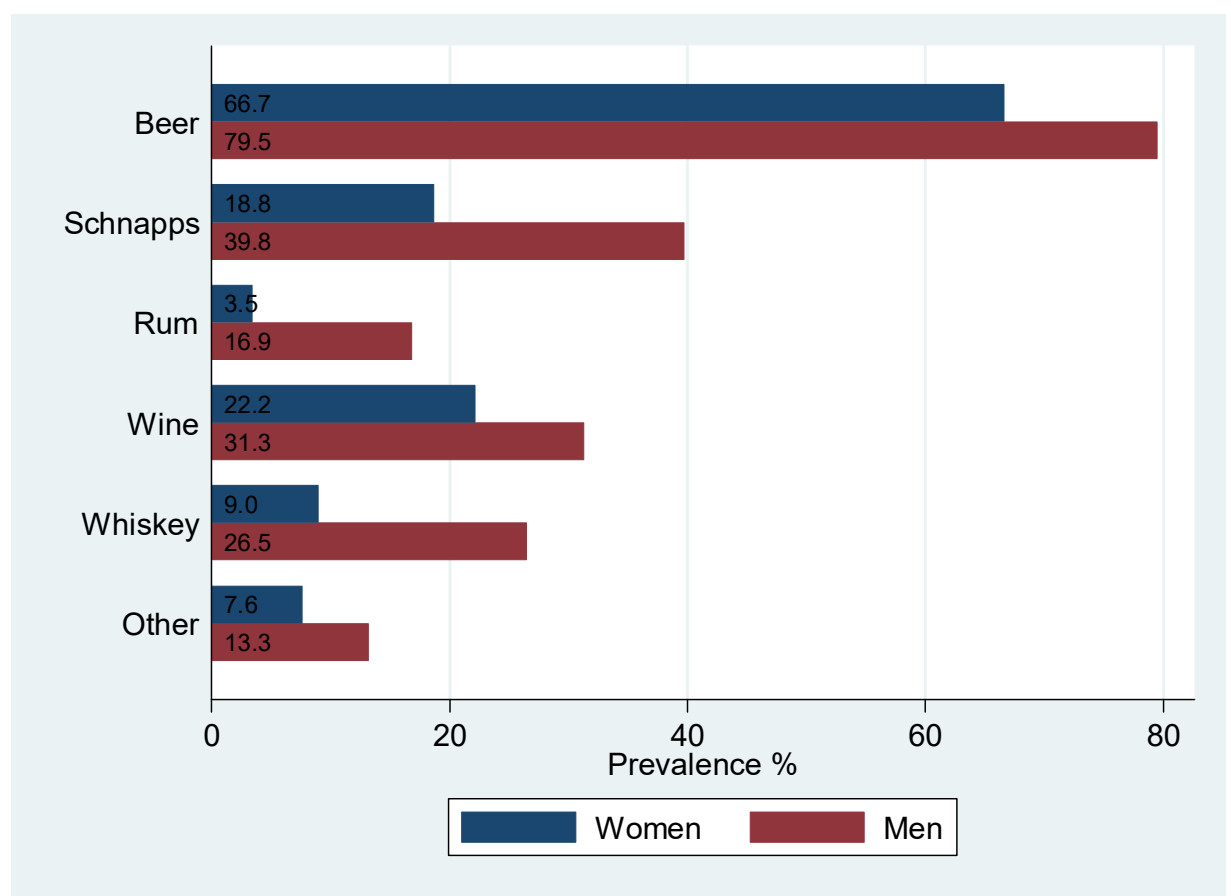

Figure 1. Frequency (\%) of the consumption of alcoholic beverages during the month prior to the survey, according to sex, by workers in a health care institution in Colombia.

Figure 2 shows alcohol consumption in grams per week and the level of triglycerides of the participants in this study. After roughly 50 years of age, both the grams of alcohol consumed and the levels of triglycerides were found to increase to above normal values (hypertriglyceridemia).

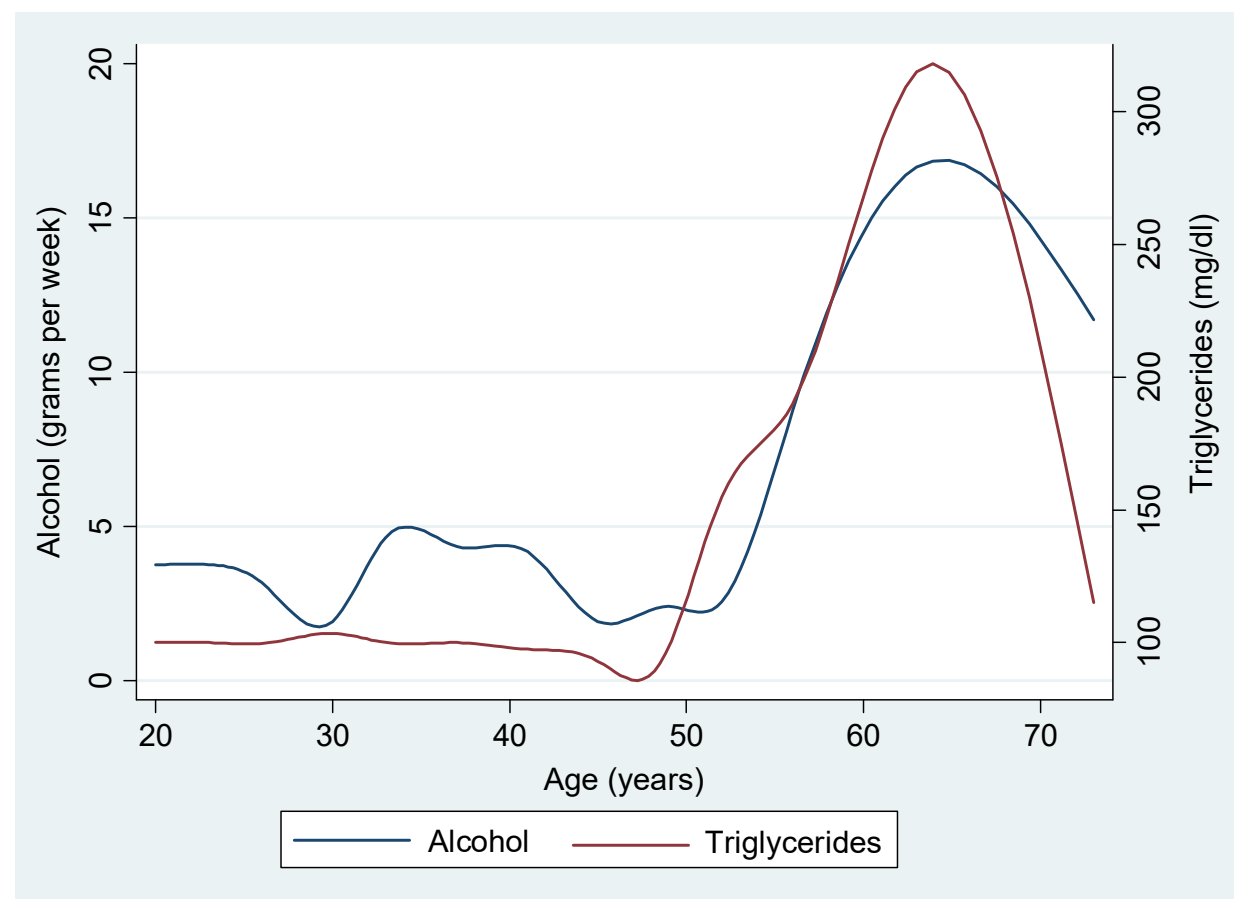

Figure 2. Alcohol Consumption and Triglyceride Levels, by Age

\section{Discussion}

This study's findings show that roughly $75 \%$ of the study population consumed some type of alcoholic beverage 
during the month prior to the survey. And of the total variables analyzed, a statistically significant difference in alcohol consumption was found only for serum levels of triglycerides.

For men, the average consumption in our study, in grams of alcohol per week, was 10 grams below the value reported by Herran et al. for the Colombian population in 2009 (Herran \& Ardila, 2009a). Meanwhile, that same article reported a consumption of 34.1 grams of alcohol per week for women, which is $53 \%$ less than our study.

After determining the prevalences in the study sample and adjusting by sex, age, socio-economic level, schooling, and marital status, we found a relationship between a high weekly consumption of alcohol (in grams) by the workers at the health care institution studied and triglyceride levels above the normal ranges.

The association between alcohol consumption and hypertriglyceridemia has been studied for several decades. In 1974 , a study was published that concluded that the daily use of moderate amounts of alcohol significantly increases pre-existing hypertriglyceridemia, without impairing fasting or postprandial glucose or insulin levels (Ginsberg, Olefsky, Farquhar, \& Reaven, 1974).

In terms of a lifestyle of excessive alcohol consumption, our study shows that a gap exists between knowledge and practice. While the health sector's professional workers traditionally lead the discourse around health promotion and disease prevention, our findings show that in some cases alcohol consumption is excessive even in this population, which belongs to a health care institution specializing in cardiovascular diseases. This is notable given that alcohol consumption is associated with one of the most important risk factors for cardiovascular health, namely, hypertriglyceridemia, thereby reflecting what is known as the "paradox of prevention" (Schou, Storvoll, \& Moan, 2014).

Finally, one of the strengths of this study is a reduction in the measurement error as a result of using measurement instruments that were developed and validated for the Colombian population (Herran \& Ardila, 2009a; Herran \& Ardila, 2006), for the purpose of adequately characterizing the amount of alcohol consumed ( $\mathrm{g} / \mathrm{week}$ ). Another strength is that those who were responsible for the interviews and the anthropometric measurements were trained in standardized techniques.

A limitation of this study is that this was a cross-sectional study, and therefore it was not possible to establish the temporality of the relationship found between alcohol consumption and altered triglyceride levels. Thus, our results should be interpreted with caution.

Another limitation is that this study could not identify the typology of the alcohol consumer (e.g., problematic, dependent, safe limit) (Loughlin \& Kayson, 1990); rather, it determined the weekly amount of alcohol consumed. In addition, our study did not analyze factors such as genetics and diet, which could have a significant effect. However, the association that was found is relevant and should be taken into account.

Furthermore, although the sample analyzed in this study is specific given its characteristics as health workers and its particular social, cultural and demographic context, which could limit its external validity, we consider that there is a potential impact of our findings on global health in the measure that these contribute to the generation of solid evidence regarding the triad composed by knowledge, self-care and counseling in health education, meaning that the results of this study highlight, once again, the incoherence between what health professionals know and their lifestyle practices such as the alcohol consumption.

\section{Conclusions}

In conclusion, this population consumed 70 grams $( \pm 69.4 \mathrm{~g})$ of alcohol per week, on average, which is equivalent to drinking roughly two 1-ounce glasses of an alcoholic beverage. Our study also found that a high consumption of grams of alcohol per week by the workers in the health care institution studied was related to triglyceride levels above the normal ranges.

While the association between the consumption of alcohol and the condition of being a worker has already been studied, and has been described according to sociodemographic factors, violence, and absence from work (Chagas, Gaunekar, Patel, Kukalekar, \& Fernandes, 2003; Lapham, Gregory, \& McMillan, 2003; Loughlin \& Kayson, 1990; Ramírez, Martínez, \& del Barco, 2011), no evidence has previously been reported of a relationship between alcohol consumption and hypertriglyceridemia in workers in the health sector. Therefore, this study's findings provide an important contribution to the scientific literature, and will enable implementing interventions or programs related to the responsible consumption of alcohol by workers, especially for those who work in the health field.

\section{Competing Interests Statement}

The authors declare that there are no competing or potential conflicts of interest. 


\section{References}

American Diabetes Association. (2014). Standards of medical care in diabetes-2014. Diabetes Care, 37, S14-S80. https://doi.org/10.2337/dc14-S014

American Psychiatric Association. (1994). Diagnostic and statistical manual of mental disorders (4th ed.). Washington, DC: American Psychiatric Association.

Ardila, M. F., \& Herrán O. F. (2008). Expectativas en el consumo de alcohol en Bucaramanga, Colombia. Revista Medica de Chile, 136(1), 73-82. http://dx.doi.org/10.4067/S0034-98872008000100009

CDC. EpiInfo, versión 6.04d. Epidemiología en ordenadores. Atlanta, Georgia. Enero, 2001.

Chagas, M., Gaunekar, G., Patel, V., Kukalekar, D. S., \& Fernandes, J. (2003). The prevalence and correlates of hazardous drinking in industrial workers: a study from Goa, India. Alcohol Alcohol, 38(1), 79-83.

Corrao, G., Rubbiati, L., Bagnardi, V., Zambon, A., \& Poikolainen, K. (2000). Alcohol and coronary heart disease: a meta-analysis. Addiction, 95, 1505-23. https://doi.org/10.1046/j.1360-0443.2000.951015056.x

Gamboa, E. M., Rojas, L. Z., Bermon, A., Rangel, Y. A., Jaraba, S. J., Serrano, N. C., \& Vega, E. (2015). Cardiovascular risk and its associated factors in health care workers in Colombia. A Study Protocol. JMIR Research Protocol, 4(3), e94, 1-9. https://doi.org/10.2196/resprot.4111.

Ginsberg, H., Olefsky, J., Farquhar, J. W., \& Reaven, G. M. (1974). Moderate Ethanol Ingestion and Plasma Triglyceride Levels: A Study in Normal and Hypertriglyceridemic Persons. Annals of Internal Medicine, 80, 143-149. https://doi.org/10.7326/0003-4819-80-2-143

Greenland S. (1989). Modeling and variable selection in epidemiologic analysis. American Journal of Public Health, 79, 340-49.

Gronbaek, M., Becker, U., Johansen, D., Tonnesen, H., Jensen, G., \& Sorensen, T. I. (1998). Population based cohort study of the association between alcohol intake and cancer of the upper digestive tract. British Medical Journal, 317, 844-48.

Haver, B., Gjestad, R., Lindberg, S., \& Franck, J. (2009). Mortality risk up to 25 years after initiation of treatment among 420 Swedish women with alcohol addiction. Addiction, 104, 413-9. https://doi.org/10.1111/j.1360-0443.2008.02479.x.

Herrán, O. F., \& Ardila, M. F. (2005). Consumo de alcohol, riesgo de alcoholismo y alcoholismo en Bucaramanga, Colombia, 2002-2003. Colombia Medica, 36,158-67.

Herrán, O. F., \& Ardila, M. F. (2006). Validity and Reproducibility of two Semi-Quantitative Alcohol Frequency Questionnaires for Colombian Population. Public Health Nutrition, 9, 763-770. https://doi.org/10.1079/PHN2005880

Herrán, O. F., \& Ardila, M. F. (2009a). Alcohol consumido y variables asociadas en Bucaramanga, Colombia. Revista Chilena de Nutrición, 36, 217-26. http://dx.doi.org/10.4067/S0717-75182009000300004

Herrán, O. F., \& Ardila, M. F. (2009b). Tipología de los consumidores de alcohol y sus factores determinantes en Bucaramanga, Colombia. Biomédica, 29(4), 635-646. https://doi.org/10.7705/biomedica.v29i4.141

International Diabetes Federation. (2006). The IDF consensus worldwide definition of the Metabolic Syndrome. 2006. Retrieved from http://www.idf.org/metabolic-syndrome [accessed 2017-07-20] [WebCite Cache ID 6aAe4pohI].

Karolinska Institute. (2005). Guidelines for data processing and analysis of the International Physical Activity Questionnaire (IPAQ).

Lapham, S. C., Gregory, C., \& McMillan, G. (2003a). Impact of an alcohol misuse intervention for health care workers-1: Frequency of binge drinking and desire to reduce alcohol use. Alcohol Alcohol, 38(2), 176-182. https://doi.org/10.1093/alcalc/agg047

Lapham, S. C., McMillan, G., \& Gregory, C. (2003b). Impact of an alcohol misuse intervention for health care workers 2: Employee assistance programme utilization, on-the-job injuries, job loss and health services utilization. Alcohol Alcohol, 38(2), 183-188. https://doi.org/10.1093/alcalc/agg047

Lear, S. A., James, P. T., Ko, G. T., \& Kumanyika, S. (2010). Appropriateness of waist circumference and waist-to-hip ratio cutoffs for different ethnic groups. European Journal of Clinical Nutrition, 64(1), 42-61. https://doi.org/10.1038/ejen.2009.70

Loughlin, K. A., \& Kayson, W. A. (1990). Alcohol consumption and self-reported drinking-related problem 
behaviors as related to sex, work environment, and level of education. Psychological Reports, (67), 1323-1328. https://doi.org/10.2466/pr0.1990.67.3f.1323

Mantilla, S. C., \& Gómez-Conesa, A. (2007). El Cuestionario Internacional de Actividad Física. Un instrumento adecuado en el seguimiento de la actividad física poblacional. Revista Iberoamericana de Fisioterapia y Kinesología, 10(1), 48-52. https://doi.org/10.1016/S1138-6045(07)73665-1

Miguel Soca, P. E. (2009). Dislipidemias. ACIMED, 20(6), 265-273.

Ministerio de Salud y Protección Social. Estrategia nacional de respuesta integral frente al consumo de alcohol en Colombia. Documento elaborado en el Marco del Convenio Interadministrativo 080 de 2011 entre el Ministerio de Salud y Protección Social y la Universidad Nacional de Colombia y revisado y retroalimentado en el marco del Convenio Interadministrativo 479 de 2013 Ministerio de Salud y Protección Social Universidad Nacional de Colombia. 2013.

Ministerio de Salud. Resolución 008430 (1993). Por la cual se establecen las normas científicas, técnicas y administrativas para la investigación en salud. Santa Fe de Bogotá: Ministerio de salud, Colombia.

Morgan, T. R., Mandayam, S., \& Jamal, M. M. (2004). Alcohol and hepatocellular carcinoma. Gastroenterology, 127(5), S87-96. https://doi.org/10.1053/j.gastro.2004.09.020.

Murray, R. P., Connett, J. E., Tyas, S. L., Bond, R., Ekuma, O., Silversides, C. K., \& Barnes, G. E. (2002). Alcohol Volume, Drinking Pattern, and Cardiovascular Disease Morbidity and Mortality: Is There a U-shaped Function?. American Journal of Epidemiology, 155, 242-8.

National Cholesterol Education Program (NCEP) Expert Panel on Detection, Evaluation, Treatment of High Blood Cholesterol in Adults (Adult Treatment Panel III). (2002). Third report of the National cholesterol education program (NCEP) expert panel on detection, evaluation, and treatment of high blood cholesterol in adults (Adult Treatment Panel III) final report. Circulation, 17, 106(25), 3143-3421.

Ochoa, E. (2011). Consumo de alcohol y salud laboral: Revisión y líneas de actuación. Medicina y seguridad del Trabajo, 57(Suppl 1), 173-187. http://dx.doi.org/10.4321/S0465-546X2011000500011

Panamerican Health Organization (PAHO). (2014). Global status report on alcohol and health -2014 . WHO Library Cataloguing-in-Publication Data (pp. 1-3).

Ramírez, D. C., Martínez, K. A., \& del Barco, A. A. (2011). Abuso de alcohol en el medio laboral, factores de riesgo para el consumo e instrumentos de valoración aplicables en la vigilancia de la salud. Medicina y Seguridad del Trabajo, 57(224), 190-209.

Rehm, J., Greenfield, T. K., \& Rogers, J. D. (2001). Average volume of alcohol consumption, patterns of drinking, and all-cause mortality: results from the US National Alcohol Survey. American Journal of Epidemiology, 153, 64-71.

Rimm, E. B., Williams, P., Fosher, K., Criqui, M., \& Stampfer, M. J. (1999). Moderate alcohol intake and lower risk of coronary artery disease: Meta-analysis of effects on lipids and hemostatic factors. British Medical Journal, 319, 1523-28. https://doi.org/10.1136/bmj.319.7224.1523

Schou, L. A., Storvoll, E. E., \& Moan, I. S. (2014). Alcohol-related sickness absence among young employees: gender differences and the prevention paradox. European Journal of Public Health, 24(3), 480-5. https://doi.org/10.1093/eurpub/cku035

The National High Blood Pressure Education Program Coordinating Committee, Chobanian, A. V., Bakris, G. L., Black, H. R., Cushman, W. C., Green. L. A., et al. (2003). American Heart Association Journal, 2003; 42. The seventh report of the Joint National Committee on Prevention, Detection, Evaluation, and Treatment of High Blood Pressure (JNC-7), 1206-1252.

World Health Organization [WHO]. (2000). Obesity: preventing and managing the global epidemic. Report of a WHO Consultation. WHO Technical Report Series 894. Geneva: World Health Organization.

World Health Organization [WHO]. (2015). Regional Status Report on Alcohol and Health in the Americas. WHO Library Cataloguing-in-Publication Data (pp. 1-80). 1

\section{Copyrights}

Copyright for this article is retained by the author(s), with first publication rights granted to the journal.

This is an open-access article distributed under the terms and conditions of the Creative Commons Attribution license (http://creativecommons.org/licenses/by/4.0/). 